\title{
REVIEWS
}

\section{GENE ACTION AND CANCER}

GENE CONTROL IN THE LIVING CELL. J. A. V. Butler. Allen and Unwin : London, 1968. Pp. 164. 36s.

This book is interesting and very readable. It reviews what is known about the control of gene action and relates this to what is known about the disorganised activities of cancer cells. The book is in two parts. The first part deals with the regulation of gene activity in microbes and normal multicellular organisms, including short chapters on gene action during development and differentiation and the problems of gene expression in cells producing antibodies. The author seems more at home when dealing with events at the molecular and cellular levels than when dealing with the physiology and development of complete multicellular organisms. Inevitably in a book of this length, intended for non-specialists as well as for specialists, there are statements which will mislead unless the relevant literature (easily accessible through the references given for each chapter) is consulted. For example on p. 50 the non-specialist might easily be left with the conclusion that adrenocorticotrophic hormone (ACTH) from the pituitary directly stimulates the adrenal gland to secrete adrenaline, whereas AGTH is responsible (indirectly) only for the production of the enzymes that synthesise adrenaline prior to its storage in the cells of the adrenal medulla.

The second part of the book starts with a lucid account of the natural history of cancers. This is followed by a series of chapters on somatic mutation, tumour viruses, the effects of hormones and radiations on normal and tumourous cells. In these the author develops his thesis that cancers result from defects in or alterations of the control of gene action and gene expression. It is therefore surprising that no mention is made of the singlegene cancers such as retinoblastoma, xeroderma pigmentosa and familial polyposis coli known in man. The second part of the book ends with a discussion of current techniques and future prospects for the therapy of cancers.

The book has an index and many, simple, clear diagrams. It also has a number of annoying misprints (e.g. gonodotropins, p. 50, hasolus, p. 71).

J. G. M. SHIRE

University of Cambridge, Department of Genetics

\section{PRIMER OF PSYCHOGENETICS}

THE GenetiC ANALYSIS OF BehaviOUR. P. A. Parsons. Methuen and Co., London, 1967. Pp. 174+x. 30s.

"This monograph" Professor Parsons tells us " is an attempt at applying evolutionary principles to behaviour". To this end, he provides us with an introduction to population genetics based largely on examples from Drosophila mating behaviour, before moving on to a consideration of the analysis of quantitative traits. A chapter on selection adduces examples from both Drosophila and rodents, and these groups are the subject of further detailed consideration in the two subsequent chapters-one on mating behaviour, especially in Drosophila, in which the evolutionary consequences are explored 